\title{
ANALISIS DINDING DIAFRAGMA PADA KONSTRUKSI BASEMENT DI JAKARTA DENGAN MENGGUNAKAN PROGRAM ELEMEN HINGGA 3 DIMENSI
}

\author{
Calvin Wijaya ${ }^{1}$, Ali Iskandar ${ }^{2}$, dan Aniek Prihatiningsih ${ }^{3}$ \\ ${ }^{1}$ Program Studi Sarjana Teknik Sipil, Universitas Tarumanagara, Jl. Letjen S. Parman No.1 Jakarta \\ Calvinwijaya1460@gmail.com \\ ${ }^{2}$ Program Studi Sarjana Teknik Sipil, Universitas Tarumanagara, Jl. Letjen S. Parman No.1 Jakarta \\ Ali.iskandar1999@gmail.com \\ ${ }^{3}$ Program Studi Sarjana Teknik Sipil, Universitas Tarumanagara, Jl. Letjen S. Parman No.1 Jakarta \\ Aniekp@ft.untar.ac.id
}

Masuk: 17-01-2020, revisi: 05-05-2020, diterima untuk diterbitkan: 13-05-2020

\begin{abstract}
Basement is an underground building that can serve as an utility room and parking space. In the basement the work can be done in various ways that also at the time of operation can give effect change in the soil around the work. The analysis was taken from the case study of basement development project in Jakarta. The construction method is the top down method. The diaphragm wall is 1 metre thick, 55 meters depth, 71.5 meters in length and 60 meters in width. This analysis will focus more on the calculation of the diaphragm wall deformation and the iternal forces that occurs in the structure that is inside the Diaphragm wall. The analysis will be assisted with 3-dimensional finite element program with modelling Mohr-Coulomb soil failure and attempted in drained conditions. Project land with a depth of 120 meters divided into 7 layers. The analysis is done in 5 stages ranging from $1^{\text {st }}$ excavation to the $5^{\text {th }}$ excavation. From the $5^{\text {th }}$ stage, the analysis results of diaphragm wall is in safe condition.
\end{abstract}

Keywords: diaphragm wall; drained analysis; finite element method (3d); Mohr-Coulomb

\begin{abstract}
ABSTRAK
Besmen adalah sebuah struktur bawah tanah yang dapat berfungsi sebagai ruangan utilitas dan tempat parkir. Dalam pengerjaan basement dapat dilakukan dengan berbagai cara yang juga pada saat pengerjaanny dapat memberikan efek perubahan pada tanah disekitar perkerjaannya. Analisis yang dilakukan diambil dari studi kasus proyek pembangungan basement di Jakarta. Metode konstruksi yang dilakukan adalah metode top down. Dinding diafragma yang diguanakan berukuran tebal 1 meter, dalam 55 meter, panjang 71.5 meter dan lebar 60 meter. Analisis ini akan lebih berfokus pada perhitungan deformasi dinding diafragma dan gaya dalam yang terjadi pada struktur yang ada di dalam dinding diafragmanya. Analisis akan dibantu dengan program elemen hingga 3 dimensi dengan pemodelan kegagalan tanah mohr-coulomb dan dicoba pada kondisi drained. tanah proyek dengan kedalaman 120 meter dibagi menjadi 7 lapisan. analisis dilakukan dalam 5 tahap mulai dari galian 1 sampai galian ke-5. Dari ke-5 tahap tersebut didapatkan hasil analisis bahwa dinding diafragma dalam kondisi aman.
\end{abstract}

Kata Kunci: dinding diafragma; analisis drained; program elemen hingga (3D); Mohr-Coulomb

\section{PENDAHULUAN}

\section{Latar belakang}

Dalam Proyek Teknik Sipil dalam perencanaan pembangunan sebuah gedung perkantoran, pertokoan, maupun apartemen, diperlukan lahan parkir yang cukup luas. Hal ini yang menjadi permasalahan tersendiri bagi pengembang karena tidak dimungkinkan lagi pembangunan secara horizontal karena keterbatasan lahan. Oleh karena itu, dibutuhkan solusi berupa pembangunan secara vertikal ke atas maupun ke bawah tanah.

Pembangunan secara vertikal ke bawah berupa penggunaan basement. Pembangunan basement sendiri memerlukan perencanaan desain dan tahapan pelaksanaan konstruksi yang akurat serta tepat. Masalah utama yang sering dihadapi adalah adanya bangunan-bangunan tinggi di sekitar basement sehingga dibutuhkan struktur dinding penahan tanah dan penunjangnya yang kokoh, karena dalam pelaksanaan galian basement pada suatu proyek pada prinsipnya harus menjaga stabilitas tanah yang artinya tidak diperbolehkan adanya pergeseran, pergerakan ataupun deformasi tak 
Dimensi

terduga pada gedung-gedung di sekitarnya yang dapat mengakibatkan keretakan atau kerusakan bahkan keruntuhan Gedung tersebut.

Pada penelitian ini dilakukan peninjauan pada salah satu proyek di Jakarta yang direncanakan memiliki basement 7 lantai hingga kedalaman 27 meter dan dinding diafragma sedalam 55 meter. Serta kawasan disekitar proyek adalah kawasan padat penduduk sehingga pelaksanaan harus dilakukan secara efisien dan efektif agar tidak menganggu penduduk sekitar, Oleh karena itu penulis akan menganalisi serta membahas berapa besar deformasi dan gaya yang di terima oleh dinding diafragma melalui tegangan lateral tanah yang ada.penelitian ini akan menganalisa deformasi dinding diafragma pada batas yang aman dan gaya dalam dinding serta nilai safety factor

Penelitian yang dilakukan perlu dibatasi agar fokus permasalahan dan tujuan penelititan tetap tercapai. Adapun batasan-batasan pada penelitian ini adalah Lokasi dari studi kasus yang diteliti merupakan proyek gedung bertingkat di Jakarta, melakukan analisa data tanah proyek, proyek ini direncanakan memiliki 7 lantai basement, metode galian dalam pada proyek ini adalah metode top down, dinding penahan tanah yang digunakan adalah dinding diafragama dengan ketebalan 1 meter dan kedalaman 55 meter, analisis galian dalam dalam kondisi drained, Perhitungan dilakukan pada kondisi static, tidak memperhitungkan kondisi dynamic, perubahan muka air tanah dalam area galian diperhitungkan, tidak meninjau penurunan muka air di luar area, dilakukan analisis deformasi dan gaya momen pada dinding diafragma menggunakan bantuan program elemen hingga 2D dan 3D, dan menggnakan metode MohrCoulomb yang di modifikasi.

Dari penelitian tersebut diharapkan dapat mengetahui besar deformasi yang dapat terjadi pada dinding diafragma, besar gaya momen yang dapat terjadi pada dinding diafragma dan nilai safety factor yang terjadi pada setiap tahap galian.

\section{Berat jenis tanah $\left(\gamma_{\text {sat }}\right)$ dan kadar air $(w)$}

Ou (2006) menyatakan bahwa berat satuan dan kadar air dari tanah berkorelasi dengan derajat kepadatan, derajat saturasi, komposisi mineral dan kedalaman tertentu. Secara teori, komposisi mineral ddan derajat kepadatan di suatu perkotaan yang sama tidak jauh berbeda. Oleh karena itu, saat tanah disuatu tempat mendekati $100 \%$ jeuh, maka berat satuan jenuh dan kadar air akan sangat serupa. Tetapi, semakin dalam lapisan, maka semakin besar berat satuan dan semakin kecil kadar air.

\section{Drained shear strength of soils}

Terzaghi (1996) Berdasarkan effective stress principle, ketahanan maksimum geser pada tanah bukan merupakan fungsi dari tegangan normal, tetapi perbedaan antara tegangan antara normal dan tekanan air pori, seperti ketika tanah digali, volume tanah berubah yang akan menyebabkan perubahan tekanan air pori $\Delta u=0$. Untuk partially drained atau kondisi undrained, nilai dari $\Delta u$ tergantung dari pembebanan dibandingkan dengan drainase dalam tanah. Perubahan tekanan air pori, yang disebabkan oleh perubahan tegangan pada kondisi undrained.

Pada kondisi drained, air tanah diperbolehkan untuk mengalir keluar, sehingga tanah menjadi berpermeabilitas tinggi dan beban luar bekerja dalam waktu relatif lambat. Dengan kata lain ini menunjukkan keadaan jangka panjang, dimana dapat diartikan bahwa kondisi drained merupakan kondisi saat konstruksi telah berakhir.

\section{Metode galian top-down}

Pemilihan metode galian yang tepat mempertimbangkan banyak faktor seperti anggaran konstruksi, periode konstruksi, peralatan konstruksi yang tersedia, galian lagi di proyek, luas kawasan konstruksi, gedung di sekitar proyek, jenis pondasi di sekitar proyek dan lainnya. Karena proyek ini merupakan galian yang cukup dalam dengan lahan terbatas, oleh karen itu pada proyek galian dalam ini akan menggunakan metode konstruksi galian Top-Down (Ou, 2006).

metode konstruksi top-down dilakukan dengan merakit bekisting lalu mencetak pelat lantai setelah setiap tahap galian dilakukan. Pelat lantai merupakan struktur permanen yang berguna untuk menggantikan strut baja untuk menahan tekanan tanah dari bagian belakang dinding penahan tanah. Dengan demikian, konstruksi struktur bahwa tanah dapat selesai seiring selesainya proses penggalian. Konstruksi struktur bahwa tanah ini dimulai dari atas ke bawah dan berlawanan dengan metode konstruksi konvensional. Sehingga metode ini disebut metode konstruksi top-down.

Prosedur konstruksi dari metode konstruksi top-down adalah:

1. Membangun dinding penahan tanah.

2. Memasang pondasi tiang. Letakan kolom besi diatas pondasi tiang.

3. Lanjutkan ke tahap galian pertama.

4. Mulai konstruksi pelat lantai di basement pertama.

5. Mulai membangun struktur atas.

6. Lanjutkan ke tahap galian kedua. Mulai konstruksi pelat lantai di basement lantai kedua 
7. Ulangi prosedur diatas hingga kedalaman desain .

8. Kerjakan pelat pondaso, balok dan sebagainuaya. Selesaikan basement

9. Lanjutkan proses konstruksi struktur atas sampai selsesai.

\section{Dinding diafragma penahan tanah (diaphragm walls)}

Dinding diafragma dapat disebut juga sebagai slurry walls. Metode ini digunakan pertama kali di Itali pada tahun 1950 dan telah digunakan secara luas diseluruh dunia. Dengan kemajuan teknologi, semakin banyak metode baru dan peralatan konstruksi yang dikembangkan. Seperti metode the basement wall (BW) dan metode impresa construzioni opera sepcializzate (ICOS) yang dirancang oleh dua perusahaan berbeda yaitu perusahaan Jepang dan perusahaan Itali. Metode ini seringkali digunakan di beberapa negara di asia (Ou, 2006).

Kelebihan dari metode dinding diafragama adalah :

1. Getaran rendah, tingkat bising rendah, kekakuan tinggi dan relatif deformasi yang lebih kecil.

2. Ketebalan dan kedalaman dinding dapat disesuaikan.

3. Kemampuan kedap yang baik.

4. Bisa digunakan sebagai struktur permanen.

5. Dinding diafragma dan pelat pondasi membentuk kesatuan.

Kekurangan dari metode dinding diafragma adalah:

1. Membutuhkan peralatan masal, waktu konstruksi yang panjang dan biaya yang besar.

2. Peralatan penunjang membutuhkan ruang yang besar.

3. Metode ini tidak dapat digunakan pada permukaan batu kerikil.

4. Konstruksi sulit dilakukan dalam menghadapi pasir apung.

Berikut ini adalah rumus yang akan digunakan sebagai parameter dinding penahan tanah yang akan diinput pada program elemen hingga.

Modulus elastisitas beton:

$$
\mathrm{E}_{\mathrm{c}}=4700 \sqrt{f^{\prime}} \text {. }
$$

dengan $\mathrm{E}_{\mathrm{c}}=$ modulus elastisitas beton $\operatorname{dan} f^{\prime}{ }_{c}=$ kuat tekan beton

\section{Strutting Systems}

Menurut $\mathrm{Ou}$ (2006), selain dinding penahan gravity (dinding penahan yang dapat menahan tekanan lateral dengan sendirinya), penambahan sistem penyanggan dibutuhkan dibutuhkan pada dinding penahan tanah. Pemilihan sistem penyangga tidak hanya bergantung pada besarnya gaya tekanan lateral, tetapi juga pada waktu untuk pemasangan sistem penyangga tersbut dan halangan yang mungkin terjadi pada konstruksi.

\section{Acuan SNI 8460-2017}

Untuk menentukan batas yang aman serta efektif agar deformasi dinding diafragma memenuhi syarat yang telah ditetapkan, oleh karena itu digunakan panduan Standar Negara Indonesia (SNI) dalam menentukan hasil analisis yang aman serta efektif.

\section{Toleransi defleksi dinding berdasarkan acuan SNI 8460-2017}

Toleransi defleksi dinding sangat tergantung pada kepadatan lingkungan sekitar. Dengan demikian tidak ada suatu nilai defleksi maksimum yang berlaku secara umum.

Jika lingkungan sekitar tidak mensyaratkan defleksi maksimum yang lebih ketat, defleksi maksimum $0,5 \% \mathrm{H}$ harus dianggap sebagai batas toleransi defleksi dinding.

\section{Keruntuhan Mohr-Coulomb}

Peck (1996) Tanah seperti kebanyakan material padat, akan runtuh pada saat gaya tarik atau gaya geser. Gaya tarik menyebabkan pembukaan celah yang dalam beberapa keadaan tidak diinginkan dan dapat merugikan. Tetapi dalam banyak masalah rekayasa, kegagalan akibat geser yang dipertimbangkan. Kegagalan geser dimulai pada tanah saat permukaan geser dan gaya normal bergesekan.

Lingkaran tegangan Mohr dapat digunakan untuk menggambarkan limitasi dari tekanan tanah secara horisontal yang dihasilkan oleh tekanan aktif atau tekanan pasif dari sisi dinding penahan tanah. Tekanan akan dianggap tegangan efektif dan mengabaikan efek dari gesekan/adhesi dinding (Puller, 1996). 
Jakarta Dengan Menggunakan Program Elemen Hingga 3

Dimensi

\section{METODE PENELITIAN}

\section{Prosedur analisis}

Analisis dilakukan dalam beberapa langkah sebagai berikut:

1. Mengelola dan menentukan properti material tanah dasar, dinding diafragma, strut, raft, tiang bor.

2. Pemodelan geometri tanah dasar dan dinding diafragma dan sturktur lainnya dalam bentuk 2D dan 3D.

3. Membentuk mesh lapisan tanah dalam bentuk 2D dan 3D.

4. Membentuk mesh dinding diafragma dan struktur lainnya dalam bentuk 2D dan 3D.

5. Menentukan kondisi batas (boundary condition) dalam bentuk 2D dan 3D.

6. Melakukan analisis deformasi dan gaya dalam dalam bentuk 2D dan 3D.

7. Melakukan perbandingan nilai deformasi dinding, gaya momen dinding dan nilai safety factor.

\section{HASIL DAN PEMBAHASAN}

\section{Rekap input parameter}

Berdasarkan data-data yang telah dikorelasikan, diklasifikasikan dan dianalisis dari data drilling log, sondir serta hasil uji laboratorium untuk mengetahui parameter-parameter tanah. Dan juga data-data dinding diafragma, strut, raft, tiang bor yang telah dihitung untuk mengetahui data yang hendak di input pada program elemen hingga.

\section{Rekap input parameter tanah}

Berikut ini adalah rekap input parameter tanah.

Tabel 1. Rekap input parameter tanah (1)

\begin{tabular}{cccccccc}
\hline $\begin{array}{c}\text { Lapisan } \\
\text { Tanah }\end{array}$ & $\begin{array}{c}\text { Kedalaman } \\
(\mathrm{m})\end{array}$ & N-SPT & Jenis Tanah & $\begin{array}{c}\text { Konsistensi } \\
\text { Tanah }\end{array}$ & $\begin{array}{c}\text { Poisson } \\
\text { Ratio }\end{array}$ & $\begin{array}{c}\gamma \text { unsat } \\
\left(\mathrm{kN} / \mathrm{m}^{3}\right)\end{array}$ & $\begin{array}{c}\gamma \text { sat } \\
\left(\mathrm{kN} / \mathrm{m}^{3}\right)\end{array}$ \\
\hline Lapisan 1 & $0-10$ & 5 & Silty Clay & medium & 0,35 & 16 & 18 \\
Lapisan 2 & $10-20$ & 30 & Silty Clay & very stiff & 0,3 & 18 & 20 \\
Lapisan 3 & $20-40$ & 23 & Silty Clay & very stiff & 0,3 & 18 & 20 \\
Lapisan 4 & $40-60$ & 27 & Silty Clay & very stiff & 0,3 & 18 & 20 \\
Lapisan 5 & $60-80$ & 25 & Silty Clay & very stiff & 0,3 & 18 & 20 \\
Lapisan 6 & $80-100$ & 32 & Silty Clay & hard & 0,2 & 18 & 22 \\
Lapisan 7 & $100-120$ & 25 & Silty Clay & very stiff & 0,3 & 18 & 20 \\
\hline
\end{tabular}

Tabel 2. Rekap input parameter tanah (2)

\begin{tabular}{cccccccc}
\hline $\begin{array}{c}\text { Lapisan } \\
\text { Tanah }\end{array}$ & $\begin{array}{c}\text { Kedalaman } \\
(\mathrm{m})\end{array}$ & $\mathrm{e}_{0}$ & $\begin{array}{c}\mathrm{K} \\
(\mathrm{m} / \mathrm{sec})\end{array}$ & $\begin{array}{c}\mathrm{Su} \\
\left(\mathrm{kN} / \mathrm{m}^{2}\right)\end{array}$ & $\mathrm{E}\left(\mathrm{kN} / \mathrm{m}^{2}\right)$ & $\begin{array}{c}\text { Eoed } \\
\left(\mathrm{kN} / \mathrm{m}^{2}\right)\end{array}$ & Euref \\
\hline Lapisan 1 & $0-10$ & 1,6 & $10^{-7}$ & 50 & 20000 & 32098,8 & 60000 \\
Lapisan 2 & $10-20$ & 1,75 & $10^{-7}$ & 200 & 80000 & 107692 & 240000 \\
Lapisan 3 & $20-40$ & 1,15 & $10^{-7}$ & 150 & 60000 & 80769,2 & 180000 \\
Lapisan 4 & $40-60$ & 1 & $10^{-7}$ & 175 & 70000 & 94230,8 & 210000 \\
Lapisan 5 & $60-80$ & 1 & $10^{-7}$ & 160 & 64000 & 86153,8 & 192000 \\
Lapisan 6 & $80-100$ & 1 & $10^{-7}$ & 210 & 84000 & 93333,3 & 252000 \\
Lapisan 7 & $100-120$ & 1 & $10^{-7}$ & 160 & 64000 & 86153,8 & 192000 \\
\hline
\end{tabular}


Tabel 3. Rekap input parameter tanah (3)

\begin{tabular}{|c|c|c|c|c|c|c|c|c|c|}
\hline $\begin{array}{c}\text { Lapisan } \\
\text { Tanah }\end{array}$ & $\begin{array}{l}\text { Porositas } \\
\text { (n) }\end{array}$ & $\begin{array}{l}\Phi \\
\left({ }^{0}\right)\end{array}$ & $\begin{array}{l}\Psi \\
\left(^{0}\right)\end{array}$ & $\begin{array}{c}\mathrm{C} \\
\left(\mathrm{kN} / \mathrm{m}^{2}\right)\end{array}$ & $\begin{array}{c}\mathrm{P}_{\mathrm{c}}^{\prime} \\
\left(\mathrm{kN} / \mathrm{m}^{2}\right)\end{array}$ & $\begin{array}{c}\mathrm{P}^{\prime} \\
\left(\mathrm{kN} / \mathrm{m}^{2}\right)\end{array}$ & $\begin{array}{c}\mathrm{U} \\
\left(\mathrm{kN} / \mathrm{m}^{2}\right)\end{array}$ & $\begin{array}{c}\mathrm{P}_{0}^{\prime} \\
\left(\mathrm{kN} / \mathrm{m}^{2}\right)\end{array}$ & OCR \\
\hline Lapisan 1 & 0,615 & 25 & 0 & 20 & 170 & 166 & 30 & 136 & 1,25 \\
\hline Lapisan 2 & 0,636 & 30 & 0 & 40 & 420 & 386 & 130 & 236 & 1,78 \\
\hline Lapisan 3 & 0,535 & 25 & 0 & 50 & 700 & 786 & 330 & 436 & 1,6 \\
\hline Lapisan 4 & 0,500 & 25 & 0 & 40 & 1080 & 1186 & 530 & 636 & 1,7 \\
\hline Lapisan 5 & 0,500 & 25 & 0 & 60 & 1080 & 1586 & 730 & 836 & 1,29 \\
\hline Lapisan 6 & 0,500 & 25 & 0 & 60 & 1200 & 2172 & 930 & 1076 & 1,11 \\
\hline Lapisan 7 & 0,500 & 25 & 0 & 60 & 1600 & 2386 & 1130 & 1276 & 1,25 \\
\hline
\end{tabular}

Dari tabel rekap tanah tersebut sudah didapat nilai parameter-parameter tanah untuk tiap lapisan tanah.

\section{Rekap input parameter dinding penahan tanah}

Berikut ini adalah rekap input parameter dinding diafragma

Tabel 4. Rekap input parameter dinding penahan tanah

\begin{tabular}{cccc}
\hline Parameter & Nama & Nilai & Satuan \\
\hline Jenis Perilaku & Jenis Material & Elastis & - \\
Modulus elastisitas & $\mathrm{E}$ & $2.7 \times 10^{7}$ & $\mathrm{kN} / \mathrm{m}^{2}$ \\
Tebal ekivalen & $\mathrm{t}$ & 1 & $\mathrm{~m}$ \\
Berat & $\gamma$ & 24 & $\mathrm{kN} / \mathrm{m}^{3}$ \\
Angka Poisson & $v$ & 0.18 & -
\end{tabular}

Dari tabel parameter dinding diafragma, dinding diafragma menggunakan material beton.

\section{Rekap input parameter strut}

Berikut ini adalah rekap input parameter strut (slab).

Tabel 5. rekap input parameter strut (slab)

\begin{tabular}{cccc}
\hline Parameter & Nama & Nilai & Satuan \\
\hline Jenis Perilaku & Jenis Material & Elastis & - \\
Modulus elastisitas & $\mathrm{E}$ & $2.7 \times 107$ & $\mathrm{kN} / \mathrm{m}^{2}$ \\
Tebal ekivalen & $\mathrm{t}$ & 0.3 & $\mathrm{~m}$ \\
Berat & $\mathrm{v}$ & 24 & $\mathrm{kN} / \mathrm{m}^{3}$ \\
Angka Poisson & v & 0.18 & - \\
Slab 1 & Truss & 183139.38 & $\mathrm{kN} / \mathrm{m} / \mathrm{m}$ \\
Slab 2 & Truss & 166715.18 & $\mathrm{kN} / \mathrm{m} / \mathrm{m}$ \\
Slab 3 & Truss & 666046.55 & $\mathrm{kN} / \mathrm{m} / \mathrm{m}$ \\
Slab 4 & Truss & 588505.10 & $\mathrm{kn} / \mathrm{m} / \mathrm{m}$ \\
\hline
\end{tabular}

Dari tabel parameter strut, strut menggunakan material beton. 
Analisis Dinding Diafragma pada Konstruksi Basement di

Jakarta Dengan Menggunakan Program Elemen Hingga 3

Dimensi

\section{Rekap input parameter raft}

Berikut ini adalah rekap input parameter raft.

Tabel 6. Rekap input parameter raft

\begin{tabular}{cccc}
\hline Parameter & Nama & Nilai & Satuan \\
\hline Jenis Perilaku & Jenis Material & Elastis & - \\
Modulus elastisitas & $\mathrm{E}$ & $2.7 \times 10^{7}$ & $\mathrm{kN} / \mathrm{m}^{2}$ \\
Tebal ekivalen & $\mathrm{t}$ & 2 & $\mathrm{~m}$ \\
Berat & $\gamma$ & 24 & $\mathrm{kN} / \mathrm{m}^{3}$ \\
Angka Poisson & $v$ & 0.18 & - \\
\hline
\end{tabular}

Dari tabel parameter raft, raft menggunakan material beton.

\section{Rekap input parameter tiang bor}

Berikut ini adalah rekap input parameter tiang bor. Tiang bor menggunakan point spring.

\section{Rekap input parameter king post}

Berikut ini adalah rekap input parameter king post.

Tabel 7. Rekap input parameter king post

\begin{tabular}{cccc}
\hline Parameter & Nama & Nilai & Satuan \\
\hline Jenis Perilaku & Jenis Material & Elastis & - \\
Modulus elastisitas & E & $2 \times 10^{8}$ & $\mathrm{kN} / \mathrm{m}^{2}$ \\
Berat & $\gamma$ & 76.98 & $\mathrm{kN} / \mathrm{m}^{3}$ \\
Angka Poisson & $v$ & 0.3 & - \\
\hline
\end{tabular}

King post menggunakan I-section dengan tinggi badan $\mathrm{H}=0.417 \mathrm{~m}$, lebar sayap $\mathrm{B}=0.478 \mathrm{~m}$, tebal badan tb $=0.03$ $\mathrm{m}$, tebal sayap ts $=0.06 \mathrm{~m}$, dan menggunakan material baja.

\section{Hasil analisis program elemen hingga 2 dimensi dan 3 dimensi}

Setelah semua tahapan pemodelan galian selesai dianalisis, maka dapat dikeluarkan hasil deformasi dinding diafragma, nilai momen dinding diafragma dan struktur lainnya.

\section{Gaya Dalam Dinding Diafragma 2D dan 3D}

Dari hasil analisis gaya momen pada dinding diafragma didapat hasilnya seperti pada Tabel 8. 
Tabel 8. Nilai gaya momen dinding diafragma 2D dan 3D

\begin{tabular}{ccccc}
\hline $\begin{array}{c}\text { Tahap } \\
\text { pekerjaan }\end{array}$ & $\begin{array}{c}\text { Nilai momen } \\
\text { positif maksimum } \\
(\mathrm{kNm}) 2 \mathrm{D}\end{array}$ & $\begin{array}{c}\text { Nilai momen } \\
\text { negatif maksimum } \\
(\mathrm{kNm}) 2 \mathrm{D}\end{array}$ & $\begin{array}{c}\text { Nilai momen positif } \\
\text { maksimum } \\
(\mathrm{kNm} / \mathrm{m}) 3 \mathrm{D}\end{array}$ & $\begin{array}{c}\text { Nilai momen negatif } \\
\text { maksimum }\left(\mathrm{kNm} / \mathrm{m}^{\prime}\right)\end{array}$ \\
\hline Galian 1 & 133.413 & 30.3394 & 55.6913 & 87.2452 \\
Strut 1 & 137.894 & 30.2936 & 56.3372 & 86.6482 \\
Galian 2 & 295.813 & 105.97 & 95.8017 & 118.074 \\
Strut 2 & 298.092 & 104.645 & 95.1713 & 117.843 \\
Galian 3 & 397.716 & 223.64 & 147.108 & 172.906 \\
Strut 3 & 404.005 & 226.733 & 148.666 & 172.914 \\
Galian 4 & 600.694 & 526.098 & 205.672 & 228.563 \\
Strut 4 & 604.87 & 528.415 & 205.731 & 228.547 \\
Galian 5 & 799.656 & 984.912 & 207.498 & 239.797 \\
Raft & 7372.25 & 2421.85 & 207.954 & 239.939 \\
\hline
\end{tabular}

Berdasarkan hasil analisis didapatkan nilai momen dinding diafragma lebih besar terjadi pada analisis $2 \mathrm{D}$ dibandingkan dengan nilai momen analisis 3D.

Nilai Safety Factor Dinding Diafragma 2D dan 3D

Dari hasil analisis safety factor pada dinding diafragma didapat hasilnya seperti pada Tabel 9.

Tabel 9. Nilai safety factor dinding diafragma 2D dan 3D

\begin{tabular}{ccc}
\hline $\begin{array}{c}\text { Tahap } \\
\text { pekerjaan }\end{array}$ & $\begin{array}{c}\text { Nilai safety } \\
\text { factor 2D }\end{array}$ & $\begin{array}{c}\text { Nilai safety } \\
\text { factor 3D }\end{array}$ \\
\hline Galian 1 & 3.8 & 6 \\
Galian 2 & 5.6 & 6 \\
Galian 3 & 3.6 & 4.3 \\
Galian 4 & 4.05 & 6 \\
Galian 5 & 3.6 & 5.9 \\
\hline
\end{tabular}

Berdasarkan hasil analisis diatas didapatkan nilai safety factor lebih besar terjadi pada analisis 3D dibandingkan dengan nilai safety factor analisis $2 \mathrm{D}$.

Nilai Deformasi Dinding Diafragma 2D dan 3D

Dari hasil analisis deformasi pada dinding diafragma didapat hasilnya seperti pada Tabel 10. 
Tabel 10. Nilai deformasi dinding diafrgama 2D dan 3D

\begin{tabular}{ccc}
\hline Tahap pekerjaan & Nilai deformasi dinding 2D $(\mathrm{cm})$ & Nilai deformasi dinding 3D $(\mathrm{cm})$ \\
\hline Galian 1 & 0.351379 & 0.7962432 \\
Strut 1 & 0.375195 & 0.79994 \\
Galian 2 & 0.778087 & 0.960789 \\
Strut 2 & 0.810949 & 0.96508 \\
Galian 3 & 1.31162 & 1.61433 \\
Strut 3 & 1.34157 & 1.61454 \\
Galian 4 & 2.63649 & 2.30808 \\
Strut 4 & 2.66045 & 2.30817 \\
Galian 5 & 3.42752 & 2.4163 \\
Raft & 4.31392 & 2.41598 \\
\hline
\end{tabular}

Berdasarkan hasil analisis didapatkan nilai deformasi lebih kecil terjadi pada analisis 3D dibandingkan nilai deformasi analisis 2D.

Maka dapat disimpulkan analisis 3D memiliki hasil yang lebih bagus daripada analisis 2D. karena pada anailisis 3D didapat nilai momen yang lebih kecil, nilai safety factor yang lebih besar dan nilai deformasi yang lebih kecil dibandingkan dengan analisi 2D.

\section{KESIMPULAN DAN SARAN}

\section{Kesimpulan}

1. Gaya momen pada dinding diafragma melalui analisis 2 dimensi memiliki nilai gaya momen yang lebih besar dibandingkan nilai gaya momen analisis 3 dimensi.

2. Hasil safety factor pada program elemen hingga 2 dan 3 dimensi memenuhi persyaratan angka keamanan (SF > $1.5)$.

3. Safety factor pada dinding diafragma melalui analisis 3 dimensi memiliki nilai safety factor yang lebih besar dibandingkan dengan analisis 2 dimensi. Hal ini menunjukkan analisis 3 dimensi memiliki hasil yang lebih baik dibandingkan analisis 2 dimensi.

4. Deformasi yang terjadi pada dinding diafragma dengan menggunakan analisis program elemen hingga 2 dimensi menghasilkan nilai deformasi yang lebih besar dibandingkan 3 dimensi.

5. Dari kesimpulan diatas, penulis memutuskan bahwa analisa menggunakan program elemen hingga 3 dimensi lebih baik dari pada analisa menggunakan program elemen hingga 2 dimensi. Karena memiliki nilai deformasi yang lebih kecil dan juga nilai safety factor yang lebih besar. Hal itupun tidak terlepas dari program elemen hingga yang memiliki banyak yang struktur lain yang membantu dalam memberi hasil output analisis yang lebih akurat.

\section{Saran}

1. Disarankan untuk memperhitungkan kondisi dinamik, tidak hanya statik.

2. Pada saat melakukan meshing dapat dibuat dengan lebih detail lagi agar hasil yang didapat nanti lebih akurat lagi.

3. Elemen struktur yang belum dilihat gaya-gaya dalam yang terjadi dapat ditampilkan dianalisis berikutnya.

4. Untuk analisis selanjutnya disarankan untuk memperhitungkan perubahan muka air tanah diluar area galian yang terjadi.

\section{DAFTAR PUSTAKA}

Ou, Chang-Yu. Deep Excavation Theory and Practice. Taylor \& Francis Group, 2006.

Puller, Malcolm. Deep Excavations: A Practical Manual. Amer Society of Civil Engineers, 1996.

Badan Standarisasi Nasional. SNI 8460:2017: Persyaratan Perancangan Geoteknik. Badan Standarisasi Nasional, 2017.

Terzaghi, K., et al. Soil Mechanics in Engineering Practice Third Eidition. John Wiley \& Sons, Inc, 1996. 